\title{
Um Breve Estudo Comparativo Entre as Energias Eólica e Nuclear
}

\author{
A Brief Comparative Study of the Wind and Nuclear Energy
}

\author{
Tarcísio Santos Flores ${ }^{1}$
}

${ }^{1}$ Graduando em Engenharia Química do Instituto de Ciência e Tecnologia, UFVJM, Diamantina, Brasil.

\begin{abstract}
Resumo
Trata-se de um estudo breve da É perceptível a necessidade do ser humano de utilizar a energia elétrica no mundo globalizado atual. E junto com a evolução social e industrial e além do conforto diário, veio o uso abusivo de energia. Sabendo que o Brasil utiliza-se como fonte energética originárias das hidrelétricas e que a mesma não comporta toda a demanda nacional, devem-se estudar fontes de energias que possam auxiliar a mesma. Duas alternativas energéticas limpas e baratas que podem contribuir para redução aos impactos ambientais, como efeito estufa e escassez de água são as energias eólica e nuclear. Que por sua vez, apresentam características ideais para servir como fontes alternativas para produção de energia elétrica, principalmente em época de estiagem.
\end{abstract}

Palavras-chave: Energia Eólica, Energia Nuclear, comparativo.

\begin{abstract}
It is apparent the human need to use electricity in the current globalized world. And along with the social and industrial and beyond the everyday comfort evolution came the abuse of power. Aware that Brazil is used as an energy source originating from hydroelectric and that it does not include all domestic demand, should be studied energy sources that can assist it. Two clean and cheap energy alternatives which can contribute to reducing the environmental impacts such as global warming and water shortages are wind and nuclear energy. Which again, exhibit ideal characteristics to serve as alternative sources for electricity production, mainly in the dry season.
\end{abstract}

Keywords: Wind Energy, Nuclear Energy, comparative. 


\section{Introdução}

S egundo Bermann (2008) e Maluf e Rosa (2011), no decorrer da história da humanidade percebemos a evolução do homem. Com ela, vem a necessidade de buscar fontes de energias para suprir sua existência.

No período pré-industrial, a fonte de energia básica da sociedade era a muscular. Portanto, as máquinas eram movidas pelo homem e pelos animais, pois ambas são convertidas em energia mecânica que geralmente eram utilizadas na moagem de grãos e para o bombeamento de água. (BERMANN, 2008)

Já no período industrial, há um surgimento de novas formas de obtenção de energia, provenientes da necessidade de suprir um maior consumo, devido ao funcionamento das máquinas elétricas. Uma das fontes de energia básicas da era industrial foi obtida através do carvão mineral, pois, quando queimado, apresentava uma capacidade de liberar uma grande quantidade de calor e com isso, aqueceria a água formando vapor d'água, responsável pela movimentação das máquinas a vapor, utilizadas na produção e transporte de diversos materiais. (BERMANN, 2008)

Posteriormente, o petróleo passou a ser a fonte principal de energia, devido à capacidade de mover às máquinas através de motores a combustão interna. Assim, foi através do petróleo que surgiram as primeiras usinas elétricas, pois, quando este combustível é queimado, acontece à transformação do calor em eletricidade. Estas usinas denominadas termelétricas, no século XX, foram vistas como uma forma de utilização de energia pela sociedade e pela produção industrial (SILVA et al.,2003) Juntamente com as usinas termelétricas, surgem as usinas hidrelétricas, que através da força da água geram eletricidade. Com o aumento do custo do petróleo, há uma necessidade de buscar novas fontes de energias, despertando um interesse de encontrar alguma fonte energética alternativa para suprir as necessidades e substituir as existentes.

Um dos fatores considerado de extrema importância e ao mesmo tempo de preocupação no âmbito mundial é a matriz energética atual. A mesma abrange interesses políticos, ambientais, econômicos e sociais. Isso, devido à ligação direta entre a demanda energética mundial com o excesso de utilização de energia, devido à melhoria na qualidade de vida no mundo globalizado (MALUF;ROSA, 2011).

Com o surgimento da evolução tecnológica, o homem necessita de um consumo maior de energia. É de extrema importância elaborar um planejamento estratégico energético para suprir de forma segura a disponibilidade de energia necessária para o desenvolvimento social e econômico de um país, levando em consideração a minimização de impactos causados ao ambiente, para assim, atender o aumento do consumo de energia. (BERMANN, 2008)

De acordo com os fatores discutidos até agora, é notória a necessidade de buscar novas alternativas para tentar mudar a matriz energética mundial. Uma proposta é a utilização de fontes energéticas consideradas "limpas" que são as que menos contribuem para emissão de gases que compõem o efeito estufa. A energia mecânica contida no vento, denominada energia eólica e a energia liberada numa reação nuclear, energia nuclear, são dois exemplos de fontes energéticas que não emitem substâncias poluentes para o meio ambiente e serão discutidas no presente artigo. (BERMANN, 2008)

O objetivo deste artigo é mostrar as vantagens e desvantagens do uso dessas duas formas de energia, visto que ambas compõe o parque energético brasileiro, de forma minoritária por que devemos ou não, investir em uma delas ou em ambas?

\section{A História da Energia Eólica}

No final do século XIX, teve início as primeiras tentativas de produção de energia elétrica a partir da energia eólica. Este fato foi decorrente dos efeitos da crise internacional do petróleo que ocorreu em meados da década de 1970.

A energia eólica pode ser denominada como a energia cinética contida no vento, ou seja, massas de ar em movimento. Ela pode estar disponível em todos os lugares, com uma maior eficiência em regiões que apresentam maior intensidade de ventos. Seu aproveitamento está ligado à conversão da energia em movimento de translação em rotação, juntamente ao emprego de turbinas eólicas, voltado para a geração de eletricidade, além dos cataventos que são utilizados para trabalhos mecânicos.

Com o aumento da discussão a respeito do aquecimento global, houve um aumento do interesse e de investimentos satisfatórios para viabilizar o desenvolvimento e aplicação de equipamentos em escala comercial.

Segundo dados do Centro de Referência para Energia Solar e Eólica (CRESESB), desde a década de 1990 que a energia eólica vem apresentando um crescimento no cenário energético mundial. É estimado para as próximas décadas um crescimento ainda mais significativo. Isso se deve a apresentação de alguns quesitos favoráveis a obtenção de energia, como segurança no fornecimento energético, baixo custo de produção e pequeno impacto ambiental (MARTINS et al., 2008).

Na Dinamarca, em 1976, foi instalada a primeira turbina eólica comercial ligada à rede elétrica pública. Hoje em dia já existem mais de 30 mil turbinas eólicas em operação no mundo. A Associação Européia de Energia Eólica (EWEA) estimou que a Europa apresentasse uma instalação de 4.000 MW de energia eólica até o ano 2000 e até o ano de 2005, chegasse a 11.500 MW. Essas e outras metas foram cumpridas muito antes do esperado (4.000 MW em 1996, 11.500 MW em 2001). A estimativa atual passou a ser de $40.000 \mathrm{MW}$ na Europa até 2010. Nos Estados Unidos, o parque eólico existente é da ordem 
de 4.600 MW instalados e com um crescimento anual em torno de 10\%. Estima-se que em 2020 o mundo terá $12 \%$ da energia gerada pelo vento, com uma capacidade instalada de mais de 1.200GW (WINDPOWER et al., 2003; WIND FORCE, 2003).

O formato das turbinas eólicas desde as primeiras inventadas já foi discutido e aperfeiçoado diversas vezes até chegar num formato e designer ideal. Hoje, esse formato é estabelecido e dividido em três partes básicas, a saber: a torre, o nacele e o rotor/pás.

A energia gerada em cada turbina eólica é direcionada a um transformador que se encontra geralmente presente no nacele, fazendo com que aumente a voltagem da energia elétrica produzida até os níveis favoráveis para um sistema coletor energético, levando eletricidade gerada pelo conjunto de turbinas disponíveis no parque eólico até a subestação (SALINO, 2011).

Para uma implantação de projeto de um parque eólico é necessário um estudo da questão ambiental, social e de zoneamento da região de interesse. Após o realização do estudo de caso é indispensável à licença exigida pelos órgãos competentes para assim iniciar a implantação e operação.

As condições climáticas e topográficas do local de implantação de uma usina eólica interferem diretamente na quantidade de energia contida no vento. Nela, o deslocamento do ar, pode ser causado de acordo com a diferença de temperatura e os diversos tipos de solos e terrenos.

As turbinas eólicas podem ser operadas em variações consideráveis de velocidades do vento, aproximadamente de $4 \mathrm{~m} / \mathrm{s}$ até $25 \mathrm{~m} / \mathrm{s}$, podendo assim ser instaladas e operadas de forma eficiente em locais e condições climáticas distintas, variando desde desertos a zonas árticas (GWEC, 2008).

Os países que lideram o setor de geração eólica, com suas experiências, exibem um rápido desenvolvimento da tecnologia e do mercado. Isso apresenta grandes implicações socioeconômicas. Hoje em dia, diversos estudos indicam a geração de emprego e o domínio da tecnologia como fatores tão importantes quanto à preservação ambiental e a segurança energética dos países da comunidade europeia para a continuidade dos investimentos no aproveitamento da energia eólica (RENEW e SZARKA, 2006).

Existem diversos fatores que influenciam na alteração do custo e da produtividade de uma usina eólica. Estes estão ligados ao desenvolvimento do projeto básico e executivo da mesma. Devido à energia gerada por uma turbina ser uma função do cubo da velocidade média do vento, qualquer que seja a diferença na velocidade pode ser que afete a produtividade e custo da energia proveniente das usinas. Outro parâmetro a se analisar é a escolha do tipo de turbina e fabricante que será introduzida na usina devido a algumas máquinas serem projetadas para operar de forma mais eficiente em menor velocidade de vento, enquanto que outras são destinadas a regimes de ventos mais fortes.

\section{A História da Energia Nuclear}

Outra fonte alternativa que vem se destacando no mercado é a energia nuclear, proveniente da energia contida no núcleo de átomos de materiais pesados, geralmente utiliza-se o urânio.

No fim do século XIX, descobriu-se a radioatividade. Durante muito tempo ela era vista apenas como objeto acadêmico, até que fosse levantada a possiblidade de aproveita-la. Assim, a energia proveniente de uma fissão dos átomos, inicialmente foi utilizada na confecção de bombas e também geradores de energia.

$\mathrm{Na}$ fissão nuclear, acontece à liberação da energia pela divisão do núcleo do átomo. Nela, são encontrados frequentemente em dois pedaços menores, de massas equivalentes para núcleos pesados. Existe também a fissão em mais de dois pedaços, mas, isso é muito raro. O somatório das energias dos núcleos originados, somados a energia consumida pelo ambiente presente na forma de energia cinética dos produtos de fissão e dos nêutrons liberados devem ser equivalentes à energia total do núcleo original, devido ao princípio da lei de conservação de energia.

A indução do bombeamento de núcleos pesados com um nêutron faz com que a fissão do núcleo seja mais efetiva. Devido à absorção do nêutron, o núcleo fica mais instável. Isso acontece devido raramente ocorrer fissão nuclear de forma espontânea na natureza.

O primeiro reator nuclear, utilizado para produção de energia foi construído em 1942. Isso ocorreu porque Einstein chamou a atenção do governo dos Estados Unidos para a possiblidade da produção de energia através da fissão dos átomos (CNEN, 2010).

No período da Segunda Guerra Mundial, bombas nucleares foram usadas pela primeira e única vez em guerras. Foi através do bombardeio americano que atingiu Hiroxima e Nagasaki que foi possível perceber o poder devastador dessa tecnologia. Mesmo com esses fatores desmotivadores, a produção de eletricidade via nuclear apresenta inúmeras vantagens, fazendo com que permaneça o uso da energia nuclear para esse fim. Hoje, a energia nuclear vem sendo representada como uma opção de desenvolvimento, devido a mesma ser considerada como uma fonte de energia limpa, pois seu uso proporciona uma baixa emissão do gás carbônico $\left(\mathrm{CO}_{2}\right)$, o contribuinte do efeito estufa que contribui para o aquecimento global.

O Urânio-235 $\left({ }^{235} \mathrm{U}\right)$ é um exemplo de material a ser bombardeado com um nêutron para produzir energia, ou utilizado para fabricação de uma bomba nuclear. $\mathrm{O}$ mesmo ao ser bombardeado com um nêutron fissiona em dois pedaços menores, emitindo assim geralmente dois nêutrons (GONÇALVES; ALMEIDA, 2005).

Controlando-se o número de nêutrons produzidos e 
a quantidade de ${ }^{235} \mathrm{U}$, pode-se controlar a taxa de fissão ao longo do tempo, este tipo de reação é utilizado em um reator nuclear. Já em uma bomba atômica, as fissões ocorrem todas de um intervalo de tempo muito curto, gerando uma enorme quantidade de energia liberada por esse elemento ao se fissionar (GONÇALVES; ALMEIDA, 2005).

A geração da energia elétrica é uma das principais aplicações da energia nuclear. As usinas nucleares são usinas térmicas que aproveitam o calor produzido numa fissão, levando a movimentação do vapor de água que, por sua vez, agita as turbinas levando a produção da eletricidade (SALINO, 2011).

Segundo dados do Instituto Ciência Hoje, em alguns reatores nucleares há a necessidade de um enriquecimento do urânio, que geralmente é o combustível dos reatores, o urânio muitas vezes se encontra apenas com $0,7 \%$ do isótopo ${ }^{235} \mathrm{U}$. Esse processamento chega a proporcionar um alcance em cerca de 3,5\% do isótopo. Para a produção de uma bomba nuclear este enriquecimento é superior a 90\% (GONÇALVES; ALMEIDA, 2005).

São diversas as etapas do processamento completo de obtenção do combustível nuclear, denominado como ciclo do combustível. Ele é envolto por diversas etapas, tais como: i) primeiramente é necessária a extração do minério do solo; ii) em seguida deve-se ocorrer o beneficiamento para separar o urânio de outros minérios; iii) posteriormente ocorre a conversão em gás do produto do beneficiamento; iv) depois acontece o enriquecimento do gás, no qual a proporção de ${ }^{235} \mathrm{U}$ é aumentada até o nível desejado; v) acontece reconversão do gás de urânio enriquecido para o estado de pó; vi) fabricação de pastilhas a partir da compactação do pó; vii); e por fim, a montagem dos elementos combustíveis, quando se colocam as pastilhas em cilindros metálicos que irão formar os elementos combustíveis do núcleo do reator (GONÇALVES e ALMEIDA, 2005).

O Instituto Ciência Hoje afirma também que atualmente no mundo estão em funcionamento 440 reatores nucleares voltados para a geração de energia em 31 países. Outros 33 estão em construção. Certa de $17 \%$ da geração elétrica mundial é de origem nuclear, a mesma proporção do uso de energia hidroelétrica e de energia produzida por gás. Alguns países desenvolvidos têm seu abastecimento de energia elétrica com um alto percentual de geração nuclear. Além desses reatores, funcionam mais 284 reatores de pesquisa em 56 países (GONÇALVES e ALMEIDA, 2005).

\section{A Situação da Energia Eólica no Brasil}

Segundo dados da Companhia Paulista de Força e Luz e (CPFL), no Brasil 91\% da eletricidade provêm da energia hidráulica e é perceptível o abusivo uso de uma única matéria prima que é suscetível às intempéries da natureza (WESCHENFELDER e SCHAEFFER, 2013).
O Programa de Incentivo às Fontes Alternativas de Energia (PROINFA) com o intuito de diversificar a Matriz Energética Brasileira, em 2004 instituiu um objetivo de aumentar a participação da energia elétrica produzida por empreendimentos concebidos com base em fontes eólicas, biomassa e pequenas centrais hidrelétricas $(\mathrm{PCH})$ no Sistema Elétrico Interligado Nacional (SIN).

De acordo com os dados do Centro de Referencia para Energia Solar e Eólica, o atlas do potencial eólico brasileiro envolve todo o território nacional. Com o intuído de fornecer informações para habilitar tomadores de decisão na procura e identificação de áreas adequadas para aproveitamentos eólicos elétricos (AMARANTE et al., 2011).

A Associação Brasileira de Energia Eólica afirma que existem 205 usinas até hoje instaladas, com capacidade de 5,1 GW que apresentam uma grande vantagem devido à redução de 4.383 .430 (T/ano) de $\mathrm{CO}_{2}$.

Mesmo que exista divergência entre especialistas e instituições na estimativa do potencial eólico brasileiro, a Agência Nacional de Energia Elétrica (ANEEL) afirma que existem vários estudos indicando valores extremamente consideráveis. Poucos anos atrás, as estimativas eram da ordem de 20.000 MW. Atualmente os estudos apontam valores maiores de 60.000 MW. Essas dissensões decorrem principalmente da falta de informações e das diferentes metodologias empregadas (ANEEL, 2002).

A falta de chuvas e a realidade da seca no Brasil fez com que aflorasse um interesse do governo federal em ligar usinas mais caras em outubro de 2013 no país.

A Associação Brasileira de Energia Eólica (ABEEólica), afirma que a fonte eólica complementa as usinas hidrelétricas. Contudo, elas dão segurança na transmissão da energia, em comparação com as térmicas. A matriz está sendo expandida nessa ótica, com energia segura, limpa renovável e competitiva.

No ranking internacional de produção eólica, o Brasil ocupa a $15^{\mathrm{a}}$ posição, gerando 2,5 GW. Esse tipo de usina é a quinta mais investida no país, com apenas 3\% da geração total de energia. A fonte que ainda se encontra no topo do ranking é a hidrelétrica, com $68 \%$ da cobertura. Com a evolução, o investimento na energia eólica teve um aumento, pois antes a implantação de uma usina eólica requeria muito dinheiro, com o aperfeiçoamento da mesma essa tecnologia evoluiu, tornando assim mais acessível (MELO, 2014).

Segundo a ABEEólica, a estimativa é de que, em 2015 a produção de energia eólica seria de $8 \mathrm{GW}$, com cobertura de $6 \%$ do país, enquanto a hidroelétrica seria de $94 \mathrm{GW}$, com $65 \%$. Já em 2022, o número da eólica subiria para 17 GW e 9,5\% de cobertura, enquanto a hidroelétrica teria um aumento para 119 GW e permaneceria com 65\%.

A ANEEL afirma que em setembro de 2013, havia apenas 6 centrais eólicas em operação no Brasil com capacidade instalada de $22.075 \mathrm{KW}$, portanto, percebese que a participação da energia eólica na geração de energia elétrica no país ainda é pequena. Entre essas 
centrais, as que mais se destacam é Taíba e Prainha, no estado do Ceará, representando $68 \%$ do parque eólico nacional (ANEEL, 2002).

\section{A Situação da Energia Nuclear no Brasil}

O Brasil dispõe em seu território, diversas alternativas de geração térmica, que podem servir como complementação energética na ausência da energia hidrelétrica, tais alternativas como: urânio, carvão, biomassa, petróleo e gás natural. Sabendo que cada um possui suas especificidades de uso (SILVA, 2006).

Vale a pena ressaltar que diferentemente dos combustíveis fósseis, o urânio, combustível nuclear, não tem atualmente outra aplicação industrial corrente que não seja voltado para geração de energia elétrica. Sabe-se que o Brasil possui uma das maiores reservas mundiais de urânio. Além disso, possuímos o domínio da tecnologia de enriquecimento do urânio. Isto torna-se mais relevante agora, pois o país passou a dominar o conhecimento do ciclo completo de fabricação do combustível nuclear (MARQUES, A.L.F., 2010).

Segundo dados da ANEEL, no Brasil a expansão do parque nuclear faz parte do Plano Decenal de Expansão de Energia Elétrica (2006/2015). No final da década de 60 que foi estabelecida a instalação de usinas nucleares em território nacional. Com as mesmas, o Governo Federal almejava buscar conhecimento sobre a nova tecnologia que se expandia rapidamente pelo mundo e ao mesmo tempo, resolver um problema localizado: a necessidade de complementação térmica para o suprimento de eletricidade ao Rio de Janeiro (ANEEL, 2008).

A energia nuclear é uma tecnologia viável e sustentável para o Brasil, pois a mesma permite a geração confiável de uma energia ambientalmente limpa e que não coopera para emissão dos gases contribuintes ao efeito estufa, além de não ser afetadas por variações climáticas.

O combustível usado numa usina nuclear é de origem nacional, contribuinte para minimizar vulnerabilidades no abastecimento e na proteção contra a volatilidade dos preços, não estando sujeito a flutuações do mercado internacional. Comparando uma usina nuclear com outras, percebe que a mesma ocupa uma menor área para sua implantação, podendo ainda se instalar próximo a grandes centros consumidores, eliminando a necessidade de longas linhas de transmissão (SILVA, 2006).

Uma das usinas nucleares presente no Brasil é a Angra I, que iniciou sua construção em 1972, com tecnologia norte-americana. Após três anos, em 1975, o país assinou com a República Federal da Alemanha o Acordo de Cooperação para o Uso Pacífico da Energia Nuclear. Em Julho do mesmo ano, foram adquiridas as usinas Angra II e Angra III da empresa Kraftwerk Union A.G. - KWU, subsidiária da Siemens, também alemã. No contrato previa transferência parcial de tecnologia
(ANEEL, 2008).

Somente em 1985 que Angra I entrou em operação. Ela apresentava uma potência instalada de $657 \mathrm{MW}$. Em 2000 a usina Angra II, entrou em operação com potência de $1.450 \mathrm{MW}$, mas ficou desativada durante muitos anos. A construção foi integrada no Plano Decenal de Expansão de Energia Elétrica (2006/2015) e em julho de 2008, o Instituto Brasileiro do Meio Ambiente e Recursos Naturais (Ibama) expediu licença prévia autorizando a retomada das obras. Em 2008, o ministro de Minas e Energia, anunciou a intenção do governo de construir uma usina nuclear por ano ao longo dos próximos 50 anos, o que resultaria em uma capacidade instalada total de $60 \mathrm{mil} \mathrm{MW}$. A previsão para o início da operação Angra III é para 2014, elevando a participação da capacidade nuclear instalada no Brasil de 1,98\% (2,007 GW) para 2,5\% (3,357 GW) da capacidade instalada total, considerando que esta última terá um crescimento anual de 4\% passando de $103 \mathrm{GW}$ (2008) para $130 \mathrm{GW}$ em 2014 (ANEEL, 2008).

Dados comprovam que em 2007, Angra I e Angra II responderam por $2,5 \%$ da produção total de energia elétrica no país, quantidade estabelecida de 12,3 terawatts-hora (TWh) (ANEEL, 2008).

\section{Conclusão}

Para obtermos uma visão panorâmica da situação atual, apresentamos em anexo, um quadro comparativo entre as energias eólica e nuclear mencionadas ao longo do presente artigo. Nosso objetivo é tão somente clarificar as características dos tipos de energias mencionadas.

Conclui-se com este artigo que ambas as energias trazem benefícios, mas também apresentam alguns pontos negativos. Porém, é perceptível a contribuição que ambas podem dar ao parque energético nacional e mundial.

Tanto a energia eólica quanto a nuclear vem conquistando um importante espaço no cenário nacional, pois, ambas são classificadas como energias elétricas limpas. Esta classificação desperta os interesses governamentais e empresariais que buscam investir em pesquisas e análises que viabilizem suas crescentes implantações. Essas medidas vêm de encontro à diminuição da emissão de gases contribuintes ao efeito estufa, além de minimizar o uso irracional de água utilizada em hidroelétricas.

Por fim, faz-se necessária uma conscientização do país na área energética. Precisamos urgentemente deixar de avaliar a energia apenas utilizando o preço como parâmetro. É mister pensarmos no que o meio ambiente pode se tornar daqui algum tempo.

\section{Agradecimentos}

Agradecemos ao Professor Rubens Martins Moreira 
do Centro de Desenvolvimento de Tecnologia Nuclear (CDTN) por nos receber e nos incentivar a defender e divulgar a energia nuclear.

Agradecemos ao Professor Alexandre C. Tort, do Instituto de Física da UFRJ , pelas correções, sugestões e paciência, com o nosso excesso de entusiasmo.

Agradecemos a Professora Socorro Lima Costa do Departamento de Ciências Biológicas por abraçar nosso projeto.

Agradecemos à FAPEMIG e ao CNPq, sem os quais esta pesquisa não poderia ser realizada.

Agradecemos ao Instituto de Ciência e Tecnologia (ICT) da UFVJM e a Pró-reitoria de Pesquisa e Pósgraduação da UFVJM pelo apoio logístico e confiança.

\section{Referências}

AGÊNCIA NACIONAL DE ENERGIA ELÉTRICA. (Brasília, DF). Atlas de Energia Elétrica do Brasil. Brasília, 2002.

AMARANTE, O. A. C.; ZACK, M. B. J; SÁ, A. L. Atlas do potencial eólico brasileiro, (2001).

ASSOCIAÇÃO BRASILEIRA DE ENERGIA EÓLICA (ABEEólica). Disponível em: <http://www. portalabeeolica.org.br/>. Acesso em 30 de set. 2014.

BERMANN, C. Crise ambiental e as energias renováveis. Ciência e Cultura. vol.60. no.3. São Paul. Set/2008. Disponível em: <http://cienciaecultura.bvs.br/scielo. php?script=sci_arttext\&pid=S0009-67252008000300010 > Acesso: 21 nov 2014.

COMISSÃO NACIONAL DE ENERGIA NUCLEAR (CNEN). História da Energia Nuclear. Disponível em: $<$ http://www.cnen.gov.br/ensino/apostilas/historia. pdf $>$. Acesso em 30 de set. 2014.

COMPANHIA PAULISTA DE FORÇA E LUZ (CPFL). A Crise Energética Brasileira. Disponível em: $<$ http://www.aleph.com.br/sciarts/cpfl/CPFL $\% 20$ -20Criseenergia.htm>. Acesso em 30 de set. 2014.

GONÇALVES, A. O. D.; ALMEIDA, I. P. S. Energia nuclear e seus usos na sociedade. Ciência Hoje: v.37, p.37-44, 2005.

GELLER, H. S. Revolução Energética: Politicas Para Um Futuro Sustentável. 2002. 296 f. Tese Doutorado - Interunidades em Energia EP/IEE/FEA/IF. Universidade de São Paulo, São Paulo, 2002.

MALUF, R. S.; ROSA, T. S. Mudanças climáticas, desigualdades sociais e populações vulneráveis no Brasil: construindo capacidade. Centro de referência em segurança ambiental e nutricional, 2011.

MARQUES, A. L. F. Brasil domina o ciclo completo do urânio. Disponível em: <http://info.abril.com. $\mathrm{br} /$ noticias/tecnologias-verdes/brasil-domina-ciclocompleto-do-uranio-24052010-36.shl>. Acesso em 24 de nov. 2014.

MARTINS, F. R.; GUARNIERI, R. A.; PEREIRA, E. B. O aproveitamento da energia eólica. Revista Brasileira de Ensino de Física, v. 30, (2008).

MELO, E. Nordeste é maior produtor de energia eólica no Brasil; Ceará aparece em $3^{\circ}$ no país. Disponível em: <http://tribunadoceara.uol.com.br/noticias/ceara/ nordeste-e-maior-produtor-de-energia-eolica-nobrasil-ceara-aparece-em-3o/>. Acesso em 30 de set. 2014.

SALINO, P. J. Energia Eólica no Brasil: Uma Comparação do Proinfa e dos Novos Leilões. 2011. 120 f. Monografia - Curso Engenharia Ambiental. Escola Politécnica. Universidade Federal do Rio de Janeiro. Rio de Janeiro, 2011.

SILVA, E. P.; CAMARGO, J. C.; SORDI, A.; SANTOS, A. M. R. Recursos energéticos, meio ambiente e desenvolvimento. Multi Ciência, 2003.

SILVA, N. F. Fontes de energia renováveis complementares na expansão do setor elétrico brasileiro: o caso da energia eólica, 2006.

WESCHENFELDER, F.; SCHAEFFER, L. Situação Atual e Perspectivas da Produção de Energia Elétrica a Partir da Geração Eólica no Brasil. Disponível em: $<$ http://www.ufrgs.br/ldtm/publicacoes/Artigo $\% 20$ SENAFOR\%20fran \%20W\%202013.pdf >. Acesso em 30 de set. 2014. 